\title{
RETRACTION
}

\section{Effect of glycerol supplementation during early lactation on milk yield, milk composition, nutrient digestibility and blood metabolites of dairy buffaloes - RETRACTION}

\author{
A. M. Saleem, A. I. Zanouny and A. M. Singar \\ doi:10.1017/S175173111700180X, first published online by Cambridge University Press 20 July 2017.
}

The manuscript 'Effect of glycerol supplementation during early lactation on milk yield, milk composition, nutrient digestibility and blood metabolites of dairy buffaloes' by Saleem AM, Zanouny Al and Singar AM was submitted to animal on 22 October 2016, accepted on 23 June 2017 and published on First View on 20 July 2017.

In August 2017, we received expressions of concerns from third parties about similarities with the article entitled 'Effect of glycerol supplementation on lactation performance, nutrient digestibility, and blood metabolites in early lactation of dairy buffaloes' by Saleem AM and Zanouny Al submitted to Animal Production Science on 10 March 2017 and accepted on 08 May 2017, the abstract of which was published online as Just Accepted.

The journals animal and Animal Production Science collaborated and the full articles were analysed for similarities.

The analysis revealed that the 2 articles reported the same experiments and the same results. Small divergences existed in the list of authors, in the decimals of numbers presented in the tables ( 1 or 2 decimals in animal depending on the table vs 2 decimals in Animal Production Science), and results based on fat corrected milk or nutritive values of diets (units differed between journals). These divergences, however, are minor and were explained by authors.

Authors admitted to making duplicate submissions, citing inexperience as the reason for doing so.

As a result, the article in animal, accepted at a later date, is considered as a duplicate publication.

On this basis, we have decided to retract the article.

\section{Reference}

Saleem AM, Zanouny Al and Singar AM 2017. Effect of glycerol supplementation during early lactation on milk yield, milk composition, nutrient digestibility and blood metabolites of dairy buffaloes. Animal, first published online 20 July 2017 https://doi.org/10.1017/S175173111700180X. 